\title{
Cost optimal analysis of energy refurbishment actions depending on the local climate and its variations
}

\author{
A. Magrini ${ }^{*}$, S. Lazzari ${ }^{2}$, L. Marenco ${ }^{3}$, G. Guazzi ${ }^{4}$ \\ ${ }^{1}$ Dept. Civil Engineering and Architecture, University of Pavia, Via Adolfo Ferrata, Pavia 3-27100, Italy \\ ${ }^{2}$ Dept. Architecture and Design, University of Genova, Stradone S. Agostino, Genova 37-16123, Italy \\ ${ }^{3}$ IRE S.p.A. (Infrastrutture Recupero Energia), Via XX Settembre, Genova 41-16121, Italy \\ ${ }^{4}$ ITC-CNR, Construction Technologies Institute - Italian National Research Council, San Giuliano Milanese, MI, Italy
}

Corresponding Author Email: magrini@unipv.it

https://doi.org/10.18280/mmep.050321

Received: 16 March 2018

Accepted: 2 June 2018

\author{
Keywords: \\ building energy performance, building \\ refurbishment, cost optimal methodology
}

\begin{abstract}
The cost optimal methodology indicated by the European Directive 2010/31/UE represents the starting point to support decisions for refurbishment interventions. The procedure is much more useful if considering the limited available investments from Public Authorities or privates and represents an important decision tool to define the owners' constraints and the economic commitment in the years. However, the results are usually affected by the influence of some variables, among which there are the climatic conditions, subject of the present investigation.

To quantify some effects, the best costs/benefits ratio is evaluated among some improvement scenarios built on a series of energy efficiency measures, in the climatic conditions of some locations.

The first set of calculations compares energy performance and global costs referring to climatic data taken from the Italian National Standard UNI 10349 edition 1994 and 2016. The second analysis is performed, for one location, on the basis of the two reference climatic datasets and the registered climatic data of the last 20 years.

From the results analysis, it can be observed the need of indications by the European Commission on a regularly reference climatic data updating, to guarantee in all the countries affordable calculations for the cost optimal refurbishment solutions, and on the introduction of a tolerance/confidence range to take into account the real climate variations.
\end{abstract}

\section{INTRODUCTION}

The application of the Directive 2010/31/EU on the energy performance of buildings regarding the nZEB target is a duty for new buildings, and it is indicated as suitable also for energy refurbishment [1].

In this case, the possibility to respect the limits for nZEB is subdued to cost optimal evaluations: the requirements cannot be applied with negative results of the cost-benefit analysis over the economic lifecycle of the building. The analysis results depend also on the local climate conditions and this fact is considered in the EU Directive that indicates that the costeffectiveness must be related to it.

The importance of the cost optimal approach is stated by several documents of the European Commission on strategical indications for the energy performance improvement of buildings.

A benchmarking framework based on the cost-optimal methodology was used to monitor the progress in reaching cost-optimal levels of minimum energy performance requirements [2] in 2016 and to support national setting of realistic minimum energy performance requirements for buildings. It was highlighted that the average gap between minimum energy performance requirements and cost-optimal levels was set up to $15 \%$ above the cost-optimal level in most EU countries, for building major renovation and also referring to replacement of building elements. The results of the analyses put in evidence that there is still a significant potential for cost-effective energy savings by bridging the gap between the current minimum requirements and cost-optimal levels.

Some EU founded projects are dedicated to deepen the Directive criteria and to give useful indication on the future smart strategies to develop.

Various pilot projects have applied to real case-studies the minimum requirements fixed by the Member States, in the case of nZEB new buildings and of buildings undergoing energy requalification to achieve energy performance equal or similar to those of a nZEB (i.e. schools, [3]).

Within the Concerted Action EPBD, a joint initiative between EU Member States and the EU Commission, built to contribute to the increase of EU buildings energy performance, through the exchange of knowledge and best practices among the EU countries, several initiatives have been developed [4].

The application of the European Commission indications for the calculation of the optimal levels of efficiency in terms of costs has been monitored in the various Member States, each of which is characterized by different climatic conditions, construction types and market laws. It is recognised that designers need to establish a margin that can absorb not only the variations caused by user behaviour but also by the climate [4]. 
The costs of the actions indicated by the European Directive 2010/31/UE are subdued to a verification of their real effectiveness.

Researches based on the global energy balance, like [5], put in evidence that methods to choice the priority of renovation actions need to take into account multiple performance requirements, and also climate change. The refurbishment policies should be finalised to reach several goals such as energy saving, $\mathrm{CO} 2$ emissions reduction, or increasing indoor environmental comfort. The design main targets and not only the external conditions can affect the energy use and the operational costs. Therefore their clear definition is one of the needs in the preliminary phase of the refurbishment design [5].

The updating proposal of the EU Directive 2010/31/EU underlines the importance of cyclically revising the procedures for calculating energy performance, as well as the results achieved through their application, based on a constant monitoring action [6]

Studies on the cost-optimal and nZEB refurbishment levels have been performed referring to representative climates, identifying reference targets and technical solutions that can guide the development of new energy requirements and targeted policies, such as in [7]. However, there is a diffuse absence of indications about the quality of input climatic data and the reference values updating to take into account the climate variations.

An affordable climatic dataset is indispensable to estimate the energy performance of buildings, as it represents one of the main inputs to simulate the thermal behaviour of buildings and has a significant impact on the output of the simulation.

From studies about the effects of climatic data in the calculation of the energy performance of buildings [8], the results obtained for a nearly zero-energy building show that relevant differences can be obtained. The climatic data of several locations were compared, to show the differences between two conventional climatic data set, to be used in the energy performance of buildings calculations, as stated by Italian national laws.

This aspect is complex, as all the most general indications must be customized, taking into account affordable reference data that should be frequently updated. The National Standard Organisation of each country should have a plan of climate data updating to assure the use of the same data for all the energy evaluations. As a direct consequence, the results of the calculations should be more easily comparable each other, controllable, moreover they should be a more reliable reference for the cost-benefit evaluations.

In Italy, since 1994, the National Standard UNI 10349 [9] was used as reference for the monthly means of air temperature, water vapor pressure, wind speed, and direct and diffuse solar irradiation. Also reference climatic data for building systems design were provided. The data were elaborated from series referring to the period 1951-1970. The accuracy of sensors wasn't comparable with more recent acquisitions and moreover some series were incomplete, mostly for solar radiation and relative humidity.

The UNI 10349 Standard has been updated recently, in 2016, following the indications of International standard EN ISO 15927 [10]: it contains test reference years (hourly values) and monthly average data, for 110 Italian locations, developed by the Thermotechnical Italian Committee, CTI. They can be used respectively in the dynamic simulation procedures and in the steady state method, indicated in EN ISO 13790 [11].
The need of a systematic update of the climate data can be supported to the considerations that can be done on the real global costs evaluations: a comparison between the actual economic savings obtained and the calculated one in the refurbishment design puts in evidence the influence of the real climate variations.

Therefore two main aspects are intended to be discussed: the importance of common indications on the updating of climatic data series, to perform comparable analyses in the different European countries and the reliability of the economic evaluations, which start from the energy performance calculations that are based on reference climatic data.

For a global assessment the efficiency measures to reduce the energy needs and to increase systems energy efficiency, and renewable energy use must work together [12].

The present analysis focuses on the influence of the temperature and solar radiation on the building envelope, to better highlight the effect of the climatic data on the calculations.

\section{EVALUATION PROCEDURE - COMPARISON BETWEEN TWO REFERENCE CLIMATE DATASETS}

The evaluation procedures regarding the first target have been developed as following.

STEP 1 - Choice of the climatic data set.

A wide analysis of the dataset available on the website of the Italian Thermo-technical Committee [13] and in [9], has been developed.

The attention has been focused mainly to temperature and solar radiation, and a comparison of the monthly mean data of more than 100 locations in Italy, indicated by the National Standard UNI 10349, dated 1994 and 2016 [9] has been carried out.

From the analysis, three locations have been chosen, to highlight the effects of the climatic data variations on the energy and economic evaluation, on the basis of the following criteria (some data are resumed in Table 1):

- $\quad$ same climatic zone E based on the HDD values (Bolzano, 2791, Trento, 2567, Perugia, 2289);

- $\quad$ same latitude for two locations (Bolzano, 46.4936 Trento, $46.0793^{\circ}$ ), distant approximatively $60 \mathrm{~km}$ each other, different from the third location (Perugia, 43.0977 ${ }^{\circ}$; - significant mean variation of the temperature in the winter season (from October to March), higher than 10\% $(\Delta \mathrm{T}$, column 3 , Tab. 1$)$

- significant mean variation of solar irradiation referring to the winter period, for the first two locations (Bolzano and Trento), but with opposite sign and small variation for the third location $(\Delta \mathrm{R}$, column 3 , Tab.1);

- similar maximum temperature and irradiation variations referring to the winter period, with opposite sign (column 4-5 Tab.1).

The comparison between temperature and irradiation data taken from the UNI 10349 ver.1994 and 2016 are indicated in fig. 1, 2 and 3, where can be observed the opposite sign changes for both the $\mathrm{T}$ and $\mathrm{R}$ data of the first two locations, Trento and Bolzano. 
Table 1. Climatic conditions of the three chosen locations

\begin{tabular}{|c|c|c|c|c|c|c|}
\hline $\begin{array}{l}\text { Winter season } \\
\text { climatic data }\end{array}$ & $\begin{array}{c}\text { Winter } \\
\text { Dataset } 1994\end{array}$ & $\begin{array}{c}\text { Winter } \\
\text { Dataset } 2016\end{array}$ & $\begin{array}{l}\text { 3-Percentage } \\
\text { difference } \\
\text { 2016-1994 }\end{array}$ & $\begin{array}{l}\text { 4-Max positive } \\
\text { difference } \\
\text { 2016-1994 }\end{array}$ & $\begin{array}{c}\text { 5-Max negative } \\
\text { difference } \\
\text { 2016-1994 }\end{array}$ & $\begin{array}{c}\text { 6-Mean difference } \\
\text { between absolute } \\
\text { values }\end{array}$ \\
\hline Temperature $\mathrm{T}$ & $\begin{array}{c}\text { 1a-Mean value } \\
\mathrm{T}\left[{ }^{\circ} \mathrm{C}\right]\end{array}$ & $\begin{array}{c}\text { 2a-Mean value } \\
\mathrm{T}\left[{ }^{\circ} \mathrm{C}\right]\end{array}$ & $\Delta \mathrm{T}[\%]$ & $\Delta \mathrm{T}\left[{ }^{\circ} \mathrm{C}\right]$ & $\Delta \mathrm{T}\left[{ }^{\circ} \mathrm{C}\right]$ & $\Delta \mathrm{T}\left[{ }^{\circ} \mathrm{C}\right]$ \\
\hline Bolzano & 8.2 & 9.2 & $11.85 \%$ & 2.2 & 0.3 & 1.1 \\
\hline Trento & 8.7 & 7.1 & $-17.82 \%$ & -0.1 & -2.0 & 1.4 \\
\hline Perugia & 9.5 & 8.4 & $-11.81 \%$ & -0.1 & -2.6 & 1.0 \\
\hline Irradiation $\mathrm{R}$ & $\begin{array}{c}\text { 1b-Total value } \\
\text { winter(year) } \\
\text { R [MJ.m-2] }\end{array}$ & $\begin{array}{c}\text { b-Total value } \\
\text { winter(year) } \\
\text { R [MJ.m-2] }\end{array}$ & $\Delta \mathrm{R}[\%]$ & $\begin{array}{c}\Delta \mathrm{R} \\
\text { [MJ.m-2.day-1] }\end{array}$ & $\begin{array}{c}\Delta \mathrm{R} \\
{[\mathrm{MJ} \cdot \mathrm{m}-2 . \text { day-1] }}\end{array}$ & $\begin{array}{c}\Delta \mathrm{R} \\
{[\mathrm{MJ} \cdot \mathrm{m}-2 . \text { day-1] }}\end{array}$ \\
\hline Bolzano & $361(4785)$ & $421(5064)$ & $20.95 \%$ & 2.7 & 0.9 & 1.5 \\
\hline Trento & $380(5124)$ & $324(4198)$ & $-14.00 \%$ & -0.4 & -2.3 & 1.1 \\
\hline Perugia & 385 (5267) & $391(5335)$ & $1.65 \%$ & 2.2 & -0.7 & 0.8 \\
\hline
\end{tabular}

Note: The UNI 10349 data have been corrected taking into account the position of the climatic station and the town centre

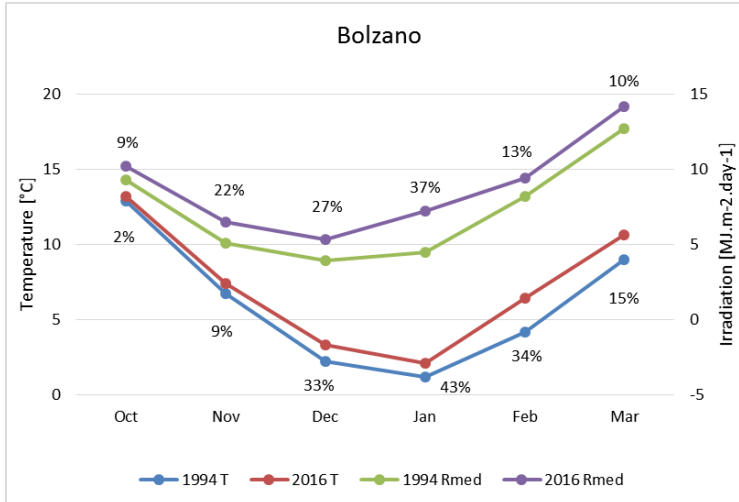

Figure 1. Bolzano - 1994 and $2016 \mathrm{~T}$ and R dataset

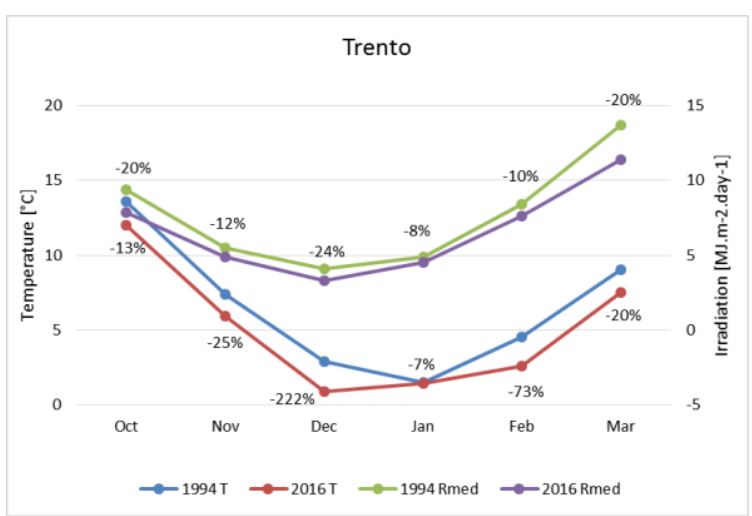

Figure 2. Trento - 1994 and $2016 \mathrm{~T}$ and R dataset

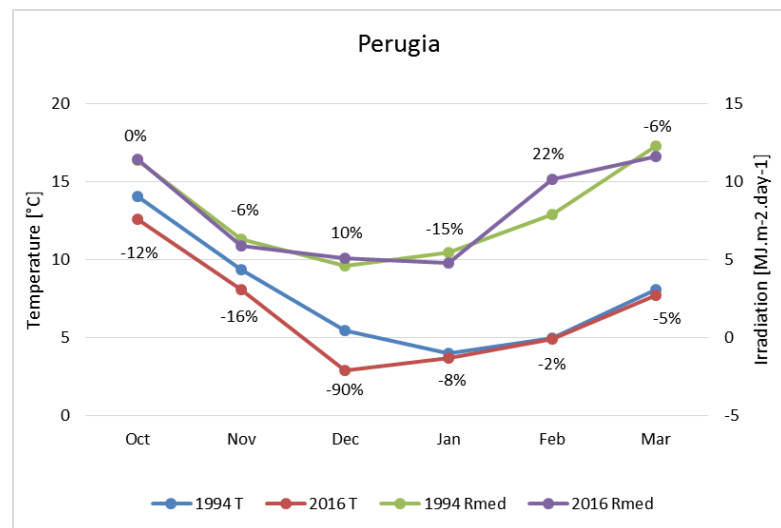

Figure 3. Perugia - 1994 and $2016 \mathrm{~T}$ and R dataset
STEP 2 - Choice of the case study. A common residential apartment in a multi-family dwelling has been considered. The main features of the case study are the same considered in [14], but the external wall orientation is here changed to South, to take into account of the solar gains in the chosen climatic conditions in the present analysis.

The apartment is characterised by net floor area of $50 \mathrm{~m}^{2}$, height $\mathrm{h}=2.70 \mathrm{~m}$, only one external wall, facing South, with three windows, two of $1.2 \mathrm{~m} \mathrm{x} 1.4 \mathrm{~m}$, and one of $1.2 \mathrm{~m} \mathrm{x} 2.2$ $\mathrm{m}$ (French window). The other boundaries border heated spaces. The existing structures are typical of the $60^{\prime}-70^{\prime}$ edification period in Italy: all single-glazed windows, thermal transmittance $\mathrm{U}_{\mathrm{w}}=4.88 \mathrm{~W} \cdot \mathrm{m}-2 . \mathrm{K}-1\left(\mathrm{U}_{\mathrm{w}}=4.97 \mathrm{~W} \cdot \mathrm{m}-2 . \mathrm{K}-1\right.$ for the French window), two different typologies of walls, with and without air layer, respectively with $\mathrm{U}=1.17 \mathrm{~W} . \mathrm{m}-2 . \mathrm{K}-1$ and $\mathrm{U}=1.63 \mathrm{~W} \cdot \mathrm{m}-2 . \mathrm{K}-1$, have been considered to highlight some differences in the refurbishment actions (Fig.4).

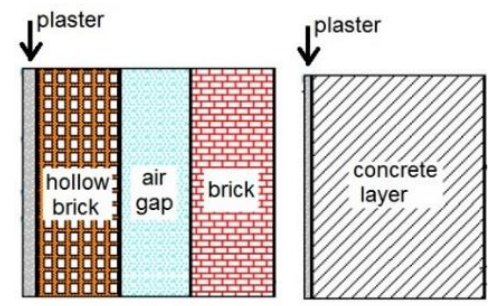

Figure 4. Existing building walls $\mathrm{W} 1$ and $\mathrm{W} 2$

STEP 3 - Reference values for the refurbishment. They have been defined referring to Italian national laws. Maximum $\mathrm{U}$-values (wall and windows) for the refurbishment and nZEB, indicated by the Italian national legislation (Table 2, ref. Table 1, Appendix B, [15]), have been considered, referring to the climatic zone E (Bolzano, Trento, Perugia) that are defined in relation to the Heating Degree Days (HDD), in the range 21013000 .

Table 2. Building envelope: U-values of the existing building and reference values (ref. Zone E)

\begin{tabular}{cccc}
\hline $\begin{array}{c}\text { U-values } \\
{\left[\mathrm{W} . \mathrm{m}^{-2} \cdot \mathrm{K}^{-1}\right]}\end{array}$ & Case-study & $\begin{array}{c}\text { Refurbishment } \\
(2021)\end{array}$ & nZEB \\
\hline Wall W1 & 1.17 & 0.28 & 0.26 \\
Wall W2 & 1.63 & 1.4 & 1.4 \\
Windows & $4.97-4.88$ & 1.4 & \\
\hline
\end{tabular}


STEP 4 - Choice of refurbishment actions.

The retrofitting actions considered in the present evaluation are focused on some insulating improvement solutions that are represented by insulation panels applied on the internal side of the external wall. The chosen materials are represented by wooden fibre board and polystyrene with thickness equal to 5 $\mathrm{cm}$ and $2 \mathrm{~cm}$ of internal plaster, to avoid excess reduction of the internal space. Moreover, it is considered that the $10 \mathrm{~cm}$ air layer of wall W1 can be filled by loose insulating material (cellulose or polyurethane foam).

The insulating materials have been chosen for their availability and also for their sustainability in terms of environmental degradation, climate change, and energy consumption. Some parameters (conductivity, density, vapour permeability) are shown in Table 3 .

Table 3. Insulating materials - Thermo-physical parameters

\begin{tabular}{cccc}
\hline Insulating materials & $\begin{array}{c}\lambda \\
{\left[\mathrm{W} \cdot \mathrm{m}^{-1} \cdot \mathrm{K}^{-1}\right]}\end{array}$ & $\begin{array}{c}\rho \\
{[\mathrm{kg} \cdot \mathrm{m}-3]}\end{array}$ & $\begin{array}{c}\delta \\
{\left[\mathrm{kg} \cdot \mathrm{m}^{-1} \cdot \mathrm{s}^{-1} \cdot \mathrm{Pa}^{-1}\right]}\end{array}$ \\
\hline \multicolumn{2}{c}{ Internal insulation } & & \\
\hline Wooden fibre board & 0.040 & 110 & $97.010^{-12}$ \\
$\quad$ Polystyrene & 0.033 & 35 & $1.310^{-12}$ \\
\hline Air layer insulation & & & \\
\hline Cellulose & 0.055 & 35 & $20010^{-12}$ \\
Polyurethane foam & 0.030 & 30 & $3.810^{-12}$ \\
\hline
\end{tabular}

External insulation wasn't taken into account, because of its higher costs that could be considered mainly when the whole façade restoration is needed.

The same level of windows retrofit has been chosen for all the cases, to reach the limit value in all the retrofitting solutions, corresponding to a double glass $4-8-4 \mathrm{~mm}$, filled with Argon, with a low emissivity surface treatment and a PVC frame.

Table 4. U-values $\left[\mathrm{W} \cdot \mathrm{m}^{-2} \cdot \mathrm{K}^{-1}\right]$ of the existing walls and of the retrofit insulated walls

\begin{tabular}{cccc}
\hline $\mathrm{N}$ & Wall and retrofit insulation & U-values & $\begin{array}{c}\text { nZEB } \\
\text { level }\end{array}$ \\
\hline 0 & W1 - Existing wall & 1.169 & \\
1 & W1 + Cellulose & 0.402 & \\
2 & W1 + Cellulose+polystyrene & 0.248 & nZEB \\
3 & W1 + Cellulose+wooden fibre & 0.265 & Refurb. \\
4 & W1 + Polystyrene & 0.417 & \\
5 & W1 + Polyurethane foam & 0.249 & nZEB \\
6 & W1 + Polyurethane foam+polystyrene & 0.180 & nZEB \\
7 & W1 + Polyurethane foam+wooden & 0.189 & nZEB \\
8 & fibre & 0.469 & \\
00 & W1 + Wooden fibre & 1.626 & \\
9 & W2 - Existing wall & 0.528 & \\
10 & W2 + Wooden fibre & 0.463 & \\
\hline
\end{tabular}

Note: $\mathrm{N}$ indicates the Scenario-number, as reported in the following figures

STEP 5 - Energy performance calculations. They have been carried on using the climatic data of the three locations, by means of a software based on monthly energy balances, following the indications of the EN ISO 13790 [11], and the national guidelines of the UNI TS 11300 [16], approximatively on the basis of the same procedure indicated in [17], here synthetized:

- Boundary conditions definition - Internal temperature has been set to $20^{\circ} \mathrm{C}$ in the heating period that has been calculated according to Italian national regulations [18]. Thermal bridges have been neglected;

- $\quad$ Existing configuration performance calculations, by using the thermal transmittances indicated for the external wall of the case study;

- Refurbishment options - Calculations: analyses of some solutions for the insulating improvement to obtain low U-values that are compared with the Refurbishment and nZEB U-values (Table 4) [14].

STEP 6 - Cost optimal evaluation. The cost-optimal assessment intends to individuate the energy performance level which leads to the lowest cost during the estimated economic lifecycle [1].

The global cost calculation for the different solutions has been carried out using the EN 15459:2017 [19], the update of the previous standard EN 15459:2007.

The new global cost equation applied is the following:

$$
\begin{aligned}
& C G=C O_{I N I T}+\sum_{j}\left[\sum _ { i = 1 } ^ { T C } \left(C O_{a(i)}(j) *\left(1+R A T_{x x(i)}(j)\right) *\right.\right. \\
& \left.D_{-} f(i)+C O_{f i n(T L S)}(j)-V A L_{f i n\left(t_{T C}\right)} t(j)\right]
\end{aligned}
$$

where:

- $C O_{\text {INIT }}$, Initial Investment Costs, achieved from the price list for the execution of public works and maintenances of the City of Milan. [20]

- $\mathrm{CO}_{a(i)}(j)$, the Annual Cost for component or service $\mathrm{j}$ for year i. Annual Costs are the sum of all costs occurring during a specific year and involve energy consumption, operational, maintenance and replacement costs of each envelope and system component.

- $R A T_{x x(i)}(j)$, the price development for year $\mathrm{i}$ for component or service $\mathrm{j}$; for the evolution of prices over the calculation period

- $D_{-} f(i)$, the discount factor for year i, calculated from a discount rate equal to $1.63 \%$, derived from the difference between the actualization rate, equal to $2.32 \%$ [21] and the inflation rate equal to $0.69 \%$ [22].

- $C O_{\text {fin }(T L S)}(j)$, the disposal cost for decommissioning, deconstruction and disposal in last year of lifecycle of component $\mathrm{j}$; this cost is the main innovation of the update Standard.

- VAL $L_{\text {fin }\left(t_{T C}\right)}$, is the residual value for component $\mathrm{j}$ at the end of the calculation period.

This new equation has been applied both to the new and the old climatic data, to better put in evidence the weight of this input. Therefore, for each retrofitting action corresponds the same global cost; in this way the change in the cost-optimality solutions depends only from the reference climatic data.

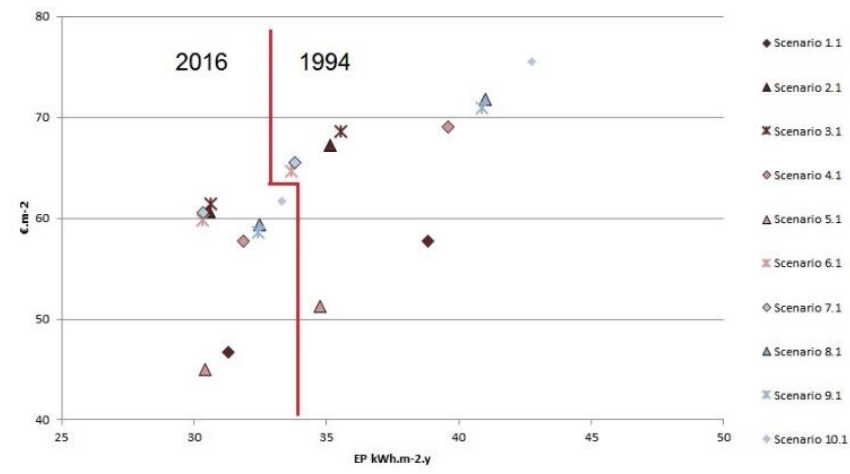

Figure 5. Cost optimal analysis for Bolzano climatic data 


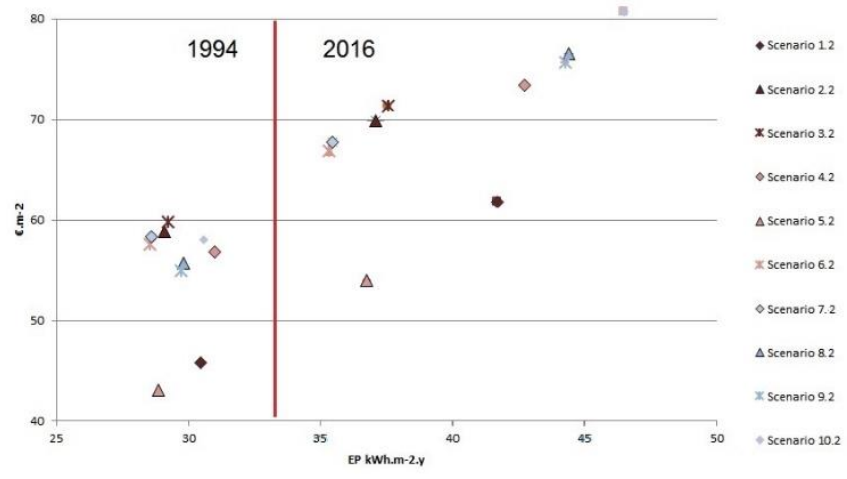

Figure 6. Cost optimal analysis for Trento climatic data

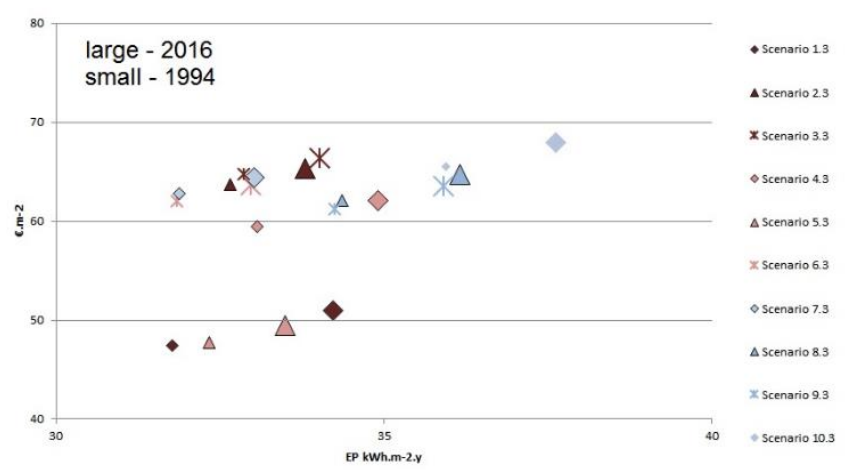

Figure 7. Cost optimal analysis for Perugia climatic data

The results of the cost-optimal investigation (Fig. 5, 6 and 7) put in evidence that for Trento and Bolzano the climatic data give a different response for the strategies to apply, on the basis of the two climatic datasets. Referring to the most recent dataset, for Bolzano (fig.5), the target in terms of energy performance is good for all the refurbishment measures and the main decision is demanded to the economic investment. The higher winter temperatures jointed with the higher irradiation values, give better results both in terms of heat losses and gains. The opposite effect can be observed for the second location, Trento (fig.6), where the updated climatic dataset gives meanly lower temperature and irradiation values. In this case some solutions, both in terms of energy consumption and costs, give unsatisfying results.

The case of Perugia (fig.7) puts in evidence that not in all locations significant differences can be observed. In this case, even if some variations have been previously evidenced, the temperature and irradiation values vary slightly, and with opposite sign. Therefore, with the two climatic dataset (indicated by smaller and larger symbols), the calculations lead to similar energy consumption values and limited costs variations.

Otherwise, from these results, it can be observed that the best cost-effectiveness solutions don't change, remaining the Scenario 1 and 5 the best ones. This confirms that, when possible, the cellulose and the polyurethane foam air gap filling represents the best insulation measure, that associates to a lower cost the best energy performance, corresponding to the nZEB goal.

From the results analysis, it is evident the important weight of the normative modification in climatic data application, since the cost-optimal diagram changes, in particular in the distributions of the scenarios.

\section{EVALUATION PROCEDURE DATASETS}

As mentioned above, the present investigation has been performed to show the need of an affordability margin or the definition of a tolerance range to be indicated together with the cost-optimal solutions.

This analysis, which is considered preliminary to a series of evaluations related to the identification of cost-optimal solutions, wants to highlight only the effect of the temperature variations. Therefore, the same case study already presented has been used, modifying the orientation from South to North, to minimise the solar gains. Further analyses will be developed later, to take into account the combined effects of temperature and solar radiation.

The comparison between the calculations performed on the basis of the reference climatic datasets of a location, for which real monthly mean data are available in a 20 years period, has been performed.

The monthly average climate data for each year from 1997 to 2017 of Genoa, HDD 1435, lat $44.4264^{\circ}$, were used, to calculate the final energy needs for heating expressed as $\mathrm{kWh} . \mathrm{m}-2$, year by year, referring to the wall $\mathrm{W} 1$ and to the Scenario 5, which represents, for walls with air layer, the best choice solution, and allows to reach the transmittance value corresponding to nZEB, in each climatic zone.

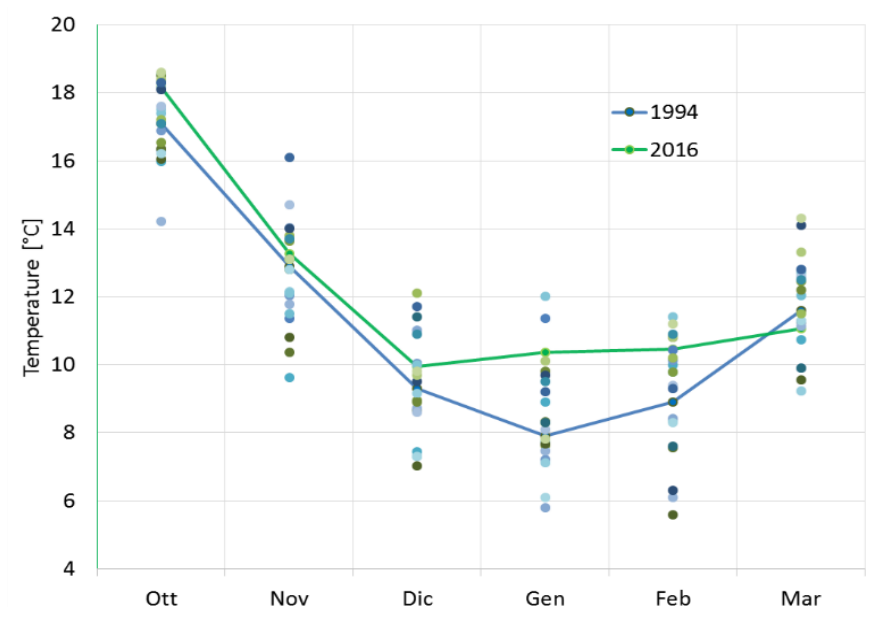

Figure 8. Genova monthly mean temperature values in a period of 20 years $(1997-2017)$

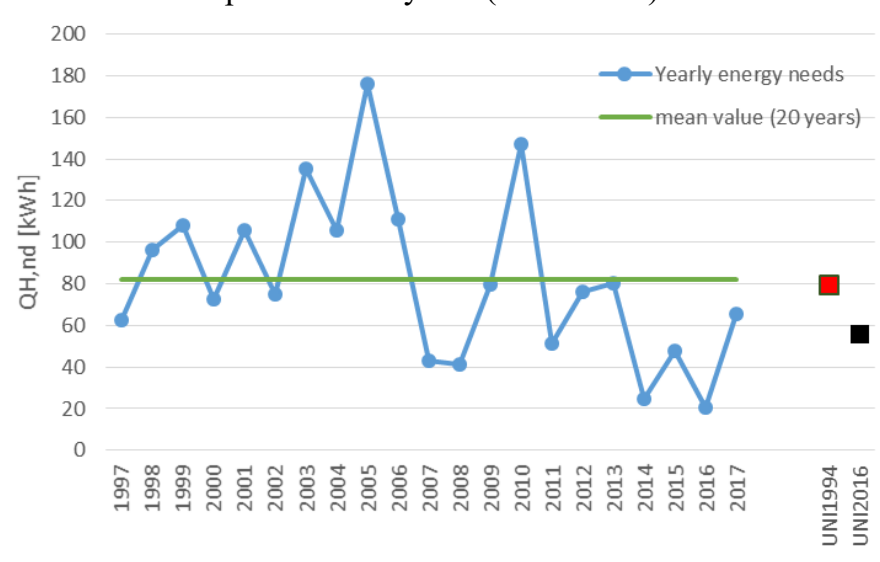

Figure 9. Energy needs referred to each year in a period of 20 years $(1997-2017)$ 
Figure 8 shows the average temperature values for each month and the reference values of the National Standard UNI 10349 ref. 1994 and 2016 (continuous lines).

The updated reference data correspond to an average temperature in January and February higher than the average values of the previous 20 years and the previous data series (1994).

Figure 9 indicates the values of the net energy needs calculated on the basis of the monthly average data for each year compared with the average value over 20 years and the values calculated with reference to the climatic datasets of UNI10349 ver.1994 and 2016.

The cost evaluation has followed the previously indicated procedure, with the data referred to the case-study, on the basis of eq.(1), assuming the energy performance indicators calculated by means of the climatic datasets corresponding to the following four scenarios:

1 - Reference climatic data taken from UNI 10349:1994;

2 - Reference climatic data taken from UNI 10349:2016;

3 - Climatic data of the year that leads to the highest energy needs in fig.9, corresponding to year 2005. The data are considered in the calculations as representing the reference climatic data over the whole period of 20 years, taken as reference for the cost- analysis;

4 - Climatic data of the year that leads to the lowest energy needs in fig.9, corresponding to year 2016 (with the same considerations as scenario 3 ).

The results show that all the cost evaluations can be included in a range (blue area in fig.10) defined by the values corresponding to the Scenario 3 and 4. In fig. 10 the results obtained by means of the conditions indicated as Scenario 1 and 2 correspond to reference climatic datasets dated 1994 and 2016. Even if the scenario 1 seems to be more representative than the more recent scenario 2, this last one is in force for the energy performance calculations.

On the basis of this climatic dataset, the lowest and the highest values of the range correspond respectively to $-6 \%$ and $+27 \%$ referring to the Scenario 2 .

Taking into account these results, in this case, performing the cost-analysis to find the cost-optimal refurbishment solution, the uncertainty margin could be considered between 6 and $27 \%$.

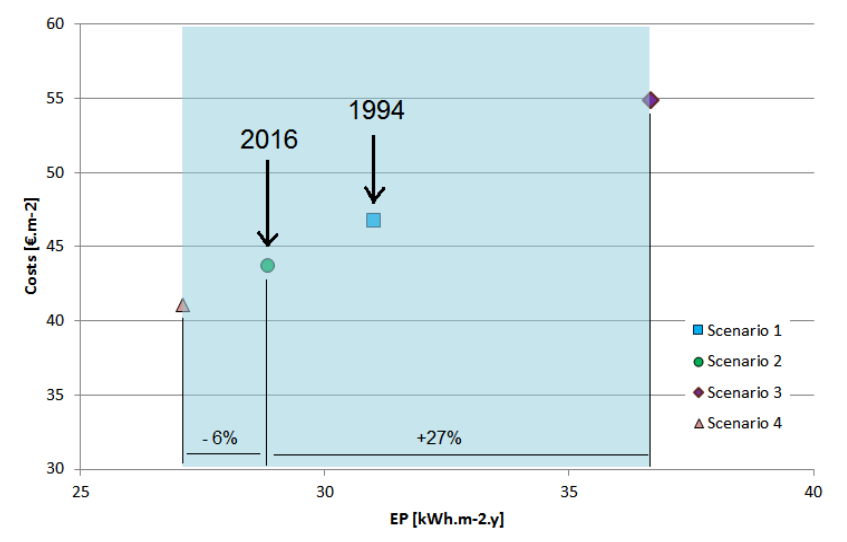

Figure 10. Cost-analysis

\section{CONCLUSIONS}

The analyses referring to the two climate series (referred to the 1994 and 2016 datasets) highlight a difference that can influence decisions on the opportunities for action and intervention. It would be suitable to establish at European Community level a procedure for periodically updating the reference climate data, if possible on a ten-year basis, so as to be able to uniformly guarantee the best intervention opportunities in all countries with regard to the most reliable climatic conditions.

The comparison between the reference datasets calculations, and the ones performed on the basis of monthly mean monitored data, allow to consider that an uncertainty margin could be suggested in the cost-optimal analysis. To quantify better the variation range, wider investigations must be developed: the obtained results represent a starting point that will be deepened in the next future.

\section{REFERENCES}

[1] EPBD. (2010). Directive 2010/31/EU of the European Parliament and of Council of 19 May 2010 on the energy performance of building (recast). Official Journal of the European Union 13-35. https://doi.org/10.3000/17252555.L_2010.153.eng

[2] EU Commission (2016). Progress by Member States in reaching cost-optimal levels of minimum energy performance requirements. COM 464 final, Brussels.

[3] Concerted Action Factsheet, Hans Erhorn, Heike ErhornKluttig. NZEB-like Educational Buildings - Pilot projects from 13 countries. https://www.epbdca.eu/archives/1668 accessed April 2018

[4] (2016). Implementing the Energy Performance of Buildings Directive (EPBD) Featuring Country Reports. ISBN 978-972-8646-32-5, C ADENE 2015. https:/www.epbd-ca.eu/ca-outcomes/2011-2015, accessed April 2018

[5] Kotireddy R, Hoes P, Hensen JLM. (2017). Robust netzero energy buildings - A methodology for designers to evaluate robustness. REHVA Journal, 9-19

[6] Draft European Parliament legislative resolution on the proposal for a directive of the European Parliament and of the Council amending Directive 2010/31 / EU on the energy performance of buildings, 17 April 2018. COM (2016) 0765 - C8-0499 / 2016 - 2016 / 0381 (COD)

[7] Zangheri P, Armani R, Pietrobon M, Pagliano L. (2017). Identification of cost-optimal and NZEB refurbishment levels for representative climates and building typologies across Europe. Energy Efficiency. https://doi.org/10.1007/s12053-017-9566-8

[8] Murano G, Corrado V, Dirutigliano D. (2016). The new Italian climatic data and their effect in the calculation of the energy performance of buildings. Energy Procedia 101: 153-160.

[9] Italian Organisation for Stardardisation (UNI). UNI 10349-1:2016, Heating and cooling of buildings Climatic data - Part 1: Monthly means for evaluation of energy need for space heating and cooling and methods for splitting global solar irradiance into the direct and diffuse parts and for calculate the solar irradiance on tilted planes.

[10] European Committee for Standardization (CEN). EN ISO 15927-4:2005 (2005). Hygrothermal performance of buildings - Calculation and presentation of climatic data - Part 4: Hourly data for assessing the annual energy use for heating and cooling. 
[11] European Committee for Standardization (CEN) EN ISO 13790 (2008). Energy performance of buildings. Calculation of energy use for space heating and cooling.

[12] Commission Recommendation (EU) 2016/1318 of 29 July 2016 on guidelines for the promotion of nearly zeroenergy buildings and best practices to ensure that, by 2020, all new buildings are nearly zero-energy buildings, Official Journal of the European Union, 2.8.2016

[13] www.CTI2000.it

[14] Magrini A, Lazzari S, Marenco L. (2017). Energy retrofitting of buildings and hygrothermal performance of building components: Application of the assessment methodology to a case study of social housing. International Journal of Heat and Technology 35(1): S205-S213.

[15] Decree of the Ministry of Economic Development (2015). Applicazione delle metodologie di calcolo delle prestazioni energetiche e definizione delle prescrizioni e dei requisiti minimi degli edifici (Application of the energy performance calculation methodologies and definition of dispositions and minimum requirements for buildings). OJ of the Italian Republic; 15 July 2015 (in Italian).

[16] Italian Organisation for Stardardisation (UNI). UNI/TS 11300 (series). Energy performance of buildings; 20102016 (in Italian).

[17] Magrini A, Lazzari S, Marenco L, Guazzi G. (2017). A procedure to evaluate the most suitable integrated solutions for increasing energy performance of the building's envelope, avoiding moisture problems. International Journal of Heat and Technology 35(4): 689699.

[18] Italian National Decree D.P.R. 412/1993, Regolamento recante norme per la progettazione, l'installazione, l'esercizio e la manutenzione degli impianti termici degli edifici ai fini del contenimento dei consumi di energia, in attuazione dell'art.4, comma 4, della legge 09.01.1991, n.10 (Regulations for the design, installation, operation and maintenance of heating systems in buildings in order to limit energy consumption, implementing article 4, paragraph 4, of Law 09.01.1991, n. 10).

[19] European Committee for Standardization (CEN). EN15459 (2017). Energy performance of buildings -

Economic evaluation procedure for energy systems in buildings.

[20] Listino prezzi per l'esecuzione di opera pubbliche e manutenzioni del Comune di Milano, edizione 2017, volume 1.1 Opere compiute civili ed urbanizzazioni e 1.2 Opere compiute impianti elettrici e meccanici (Price list for the execution of public works and maintenances of the City of Milan).

[21] https://data.worldbank.org/indicator/, 2016 update for Italy data

[22] http://it.inflation.eu/tassi-di-inflazione/italia/inflazionestorica/cpi-inflazione-italia-2018.aspx

\section{NOMENCLATURE}

$C O_{a(i)}(j)$

$C O_{f i n(T L S)}(j)$

$\mathrm{CO}_{\text {INIT }}$

$D_{-} f(i)$

$\mathrm{R}$

$R A T_{x x(i)}(j)$

$\mathrm{T}$

$\mathrm{U}$

$V A L_{f i n}\left(t_{T C}\right)$

\section{Greek symbols}

$\Delta \mathrm{R}$

$\Delta \mathrm{T}$

$\delta$

$\lambda$

$\rho$

\section{Subscripts}

W

window year $\mathrm{i}$. annual cost for component or service $\mathrm{j}$ for

disposal cost for decommissioning, deconstruction and disposal in last year of lifecycle of component $\mathrm{j}$

initial investment costs

discount factor for year i

irradiation, MJ.m ${ }^{-2}$. day ${ }^{-1}$

price development for year $i$ for component or service $\mathrm{j}$

Temperature, ${ }^{\circ} \mathrm{C}$

thermal transmittance, $\mathrm{W} \mathrm{m} \mathrm{m}^{-2} \mathrm{~K}^{-1}$

residual value for component $\mathrm{j}$ at the end of the calculation period

irradiation difference, $\mathrm{MJ} \cdot \mathrm{m}^{-2} \cdot \mathrm{day}^{-1}$ temperature difference, ${ }^{\circ} \mathrm{C}$ vapour permeability, $\mathrm{kg} \cdot \mathrm{m}^{-1} \cdot \mathrm{s}^{-1} \cdot \mathrm{Pa}^{-1}$ thermal conductivity, $\mathrm{W} \cdot \mathrm{m}^{-1} \cdot \mathrm{K}^{-1}$ density, kg.m ${ }^{-3}$ 